\title{
Effect of Co doping on structural, morphological, electrical and optical properties of nanocrystalline zinc oxide films
}

\author{
Girjesh Singh $^{1 \star}$, S. B. Shrivastava ${ }^{1}$ and V. Ganesan ${ }^{2}$ \\ ${ }^{1}$ School of Studies in Physics, Vikram University, Ujjain (M. P.) India- 456010. \\ ${ }^{2}$ UGC-DAE-Consortium for Scientific Research, Khandwa Road, Indore (M. P) India-452017. \\ Accepted 6 December, 2012
}

\begin{abstract}
We report the effect of cobalt doping on the structural, morphological, electrical and optical properties of nanocrystalline ZnO films febricated by chemical spray pyrolysis technique (CSPT). The structural studies reveals that films have strongly c-axis oriented wurtzite structure. However with the increase (at $5 \%)$ in Co doping percentage, an inclination from $\left(\begin{array}{lll}0 & 0 & 2\end{array}\right)$ to $\left(\begin{array}{lll}1 & 0 & 1\end{array}\right)$ orientation has been observed. This may be due to the fact that, in addition to substitutional sites, Co may start to occupy interstitial sites due to the deformation of lattice structure caused by substitution of nearby $\mathrm{Zn}$ atoms by other Co atoms. This will also result in an increase of lattice constant. The films appear to be homogeneous and single-phase material, where cobalt enters the $\mathrm{ZnO}$ structure as $\mathrm{Co}^{2+}$ rather than forming metallic clusters. Self-assembly of particles are clearly displayed in Atomic Force Microscope (AFM) micrograph. The particle size and roughness of the films are found to decrease with the increase in Co doping percentage. Optical transmittance spectra showed red shift at higher doping. A sharp increase in transmittance occurs at $\mathbf{3 7 5} \mathbf{n m}$ for all films, which correspond to band edge absorption. In addition to the band edge, absorption bands are also observed for all Co doped samples at 573, 606 and $666 \mathrm{~nm}$, which are attributed to $\mathrm{d}$ - $\mathrm{d}$ transitions of tetrahedrally coordinate $\mathrm{Co}^{2+}$. The absolute strength of these absorption bands increases almost linearly with the increase in Co concentrations. Band gap values are found in the interval between 3.26 to $3.16 \mathrm{eV}$. Resistance are found to decrease at $15 \%$ of Cobalt doping.
\end{abstract}

Key words: ZnO, Co, Chemical Spray Pyrolysis Technique (CSPT), Atomic Force Microscope (AFM).

\section{INTRODUCTION}

Majority of semiconductors can only absorb UV light with the wavelength equal to or less than $385 \mathrm{~nm}$. It is noted that visible light with spectral wavelength between 400 and $700 \mathrm{~nm}$ accounts for $45 \%$ of the total energy of the solar radiation, while UV light occupies less than $10 \%$ (Liao et al., 2006). Therefore, it is necessary to improve the photo catalytic efficiency for practical applications by broadening the absorption spectral range. From the view point of solid state physics, the spectral absorption is

\footnotetext{
*Correspnding author. E-mail- girijesh.s@gmail.com.
}

directly determined by the structure and moreover the band gap energies. However, semiconductors like, $\mathrm{ZnO}$ and $\mathrm{TiO}_{2}$, have shown merits of high photosensitivity, non-toxic nature and low cost (Wu and Tseng, 2006; Wang et al., 2007). Many elaboration works have been done to modify the structures of semiconductors with an aim to significantly enhance the optical absorption by doping with various metal or non-metal ions (Asahi et al., 2001; Mozia et al., 2005; Ekambaram et al., 2007; Sayilkan, 2007; Li and Haneda, 2004; Nakano et al., 2005.). Therefore, it would be interesting to investigate the effect of cobalt doping in $\mathrm{ZnO}$ films on the structure, electrical and optical properties (Wang et al., 2004; 

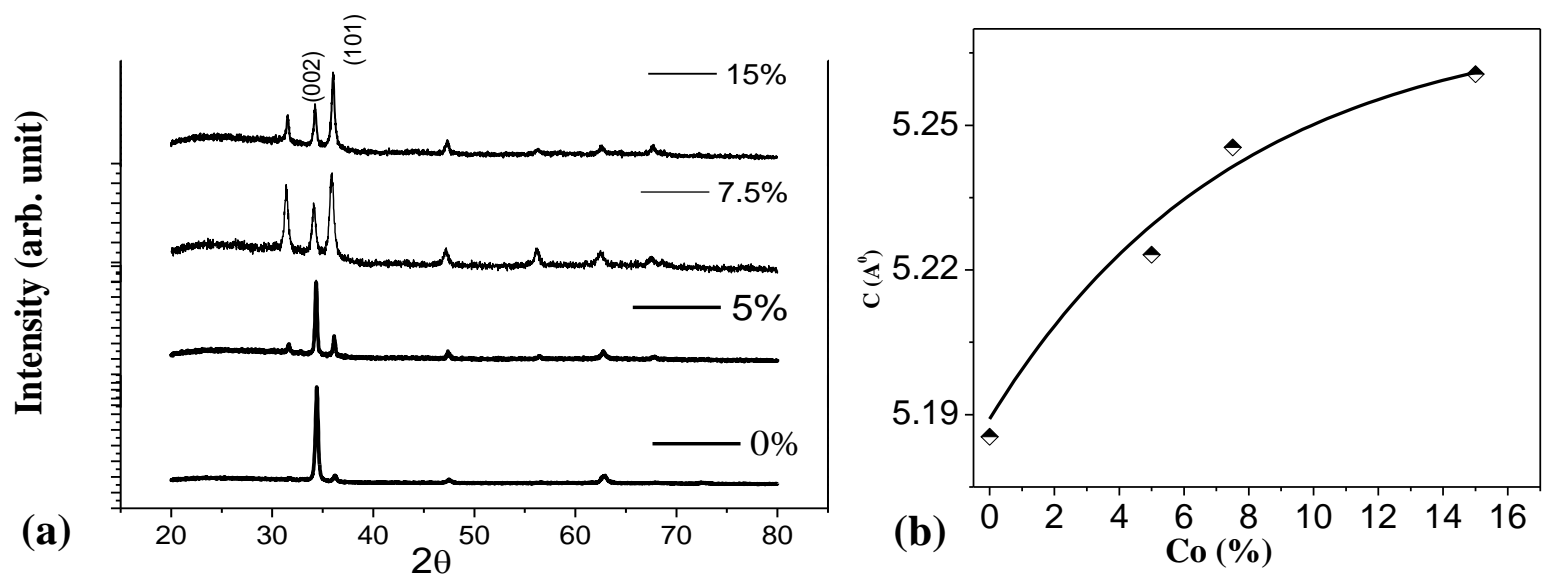

Figure 1. (a) XRD pattern of Co doped ZnO films at different Co doping cencentrations, (b) lattice constant "C" at different $\mathrm{Co}$ doping cencentrations.

Hoffmann et al., 1995). This is particularly important because $\mathrm{Co}^{2+}$ doping in $\mathrm{ZnO}$ can produce a significant red shift in band gap energy and, most importantly, the additional optical absorption bands could extend to the visible range of solar energy (Kim and Park, 2002; Qiu et al., 2006). In the present work, we report the effect of cobalt doping on the structural, morphological, electrical and optical properties of nanocrystalline $\mathrm{ZnO}$ films deposited onto glass substrate at temperature $380 \pm 5^{\circ} \mathrm{C}$ by using chemical spray pyrolysis technique (CSPT).

\section{EXPERIMENTATION}

Undoped $\mathrm{ZnO}$ and $\mathrm{Co}$ doped $\mathrm{ZnO}$ films at various dopant percentages were deposited by chemical spray pyrolysis technique (CSPT). Aqueous solution of $\mathrm{Zn}\left(\mathrm{NO}_{3}\right)_{2} \cdot 6 \mathrm{H}_{2} \mathrm{O}$ has been used for spraying. The doping was achieved by the addition of cobaltus chloride to the precursor solution, and the whole mixture was sprayed on to the microscopic glass slides. The structural and morphological characterization of the prepared film was carried out by X-ray diffractometer and Atomic Force Microscope (AFM). The electrical and optical studies have been done by using four-probe set-up and UV-Vis spectrophotometer.

\section{RESULTS AND DISCUSSION}

Figure 1(a) shows the XRD pattern of Co-doped $\mathrm{ZnO}$ films at different Co doping concentrations. XRD is done by using Rigaku Diffractrometer with $\operatorname{CuK}_{\alpha}\left(\lambda=1.5405 \mathrm{~A}^{\circ}\right)$ radiation. From the figure one can observe that the crystal structure remains hexagonal even with maximum doping that is, at $15 \%$ Co doped $\mathrm{ZnO}$. However an inclination from $\left(\begin{array}{lll}0 & 0 & 2\end{array}\right)$ to $\left(\begin{array}{lll}1 & 0 & 1\end{array}\right)$ orientation has been observed with the increase (at 7.5 and 15\%) in Co doping percentage. This may be due to fact that, in addition to substitutionl sites, Co may also start to occupy interstitial sites due to the deformation of lattice structure caused by substitution of nearby $\mathrm{Zn}$ atoms by other Co atoms. This will also result in an increase of lattice constant Figure 1 (b).

The AFM micrographs [Figure 2 (a-f)] of Co doped $\mathrm{ZnO}$ films show uniform polycrystalline nature. The selfassembly of particles (Ring and rod formation) with the increase in Co percentage are clearly shown in AFM micrograph (Figure 3). The values of roughness Figure 4 and grain size Figure 5 (a-f) are found to decrease with the increase in cobalt doping percentage.

A sharp increase in transmittance occurs at $375 \mathrm{~nm}$ for all films, which correspond to band edge absorption shown in Figure 6 . In addition to the band edge, absorption bands are also observed for all Co doped samples at 573, 606 and $666 \mathrm{~nm}$. The absolute strength of these absorption bands increases almost linearly with the increase in Co concentrations are clearly displayed in figure. This is attributed to $d$-d transitions of tetrahedrally coordinate $\mathrm{Co}^{2+}$ (Maureen et al., 2006). The values of optical band gap $\left(E_{g}\right)$ are found to vary from 3.16 to 3.26 $\mathrm{eV}$ as shown in Figure 6(b). As can be seen from the figure as the cobalt doping increases the values of band gap decreases this may be attributed to the sp-d exchange interactions between the band electrons and the localized electrons of the $\mathrm{Co}^{2+}$ ions (Diouri et al., 1986). Also, as the cobalt content increases, so does the absorption band intensity. This gives clear evidence that cobalt enters in the tetrahedral sites of the wurtzite structure as $\mathrm{Co}^{2+}$ rather than forming metallic clusters which is consistent with the XRD data. The value of resistance are found to decrease with the increase in cobalt doping percentage. This behaviour of resistance could be understood from the fact that with the increase in Co doping, initially the Co atoms occupy interstitial position thus increasing the scattering from the defects. While at higher doping the carrier concentration become much larger and it dominates the contribution from scattering and gives rise to decrease in resistance. 


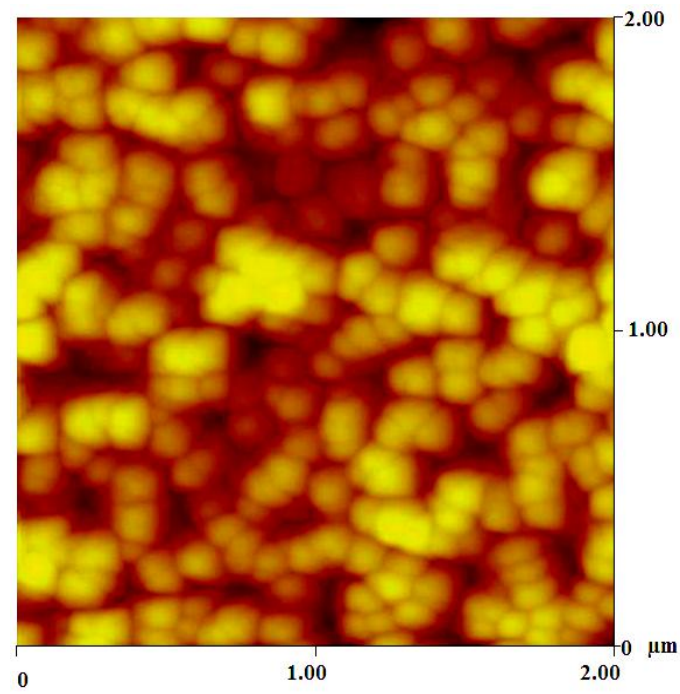

(a) $0 \%$

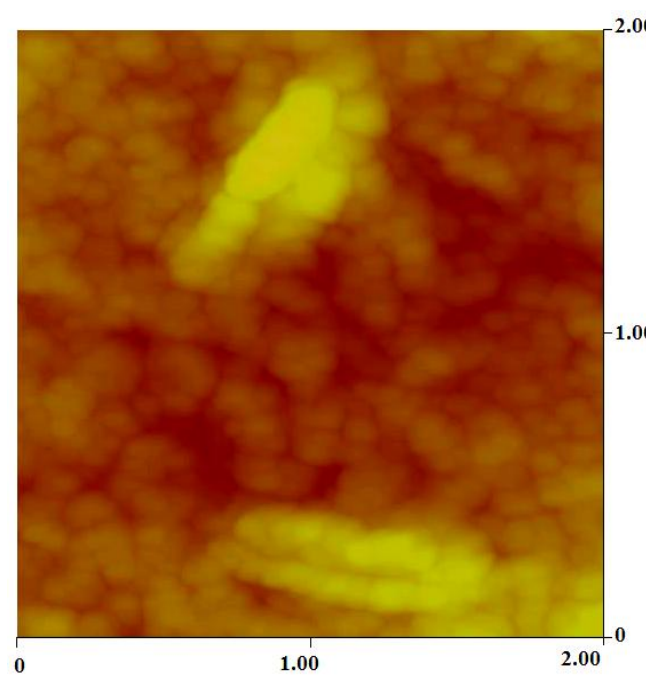

(d) $5 \%$
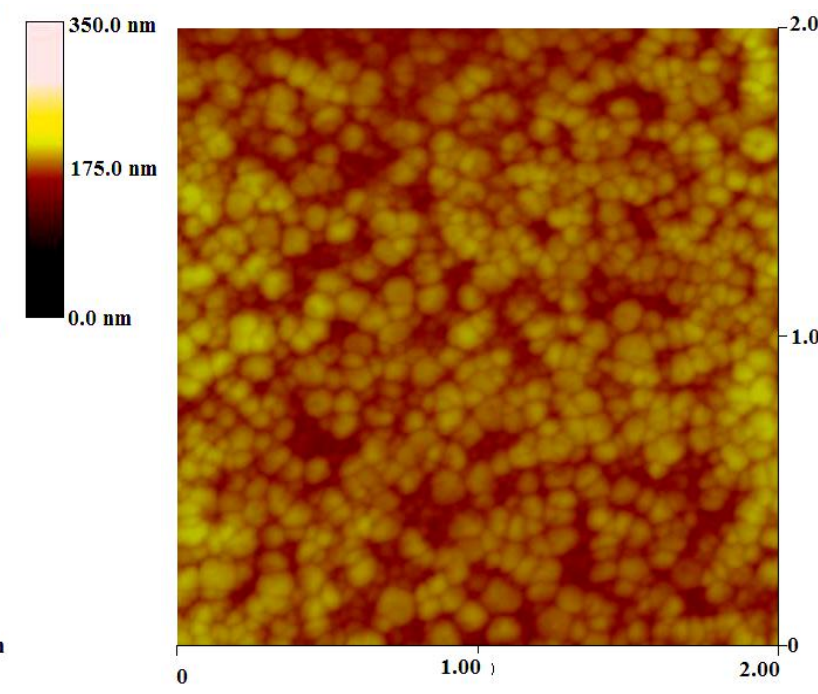

(b) $1 \%$

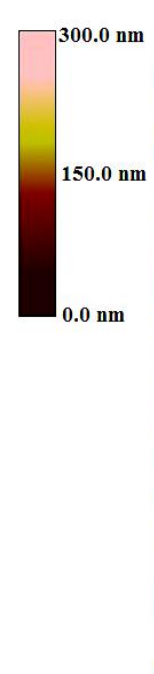

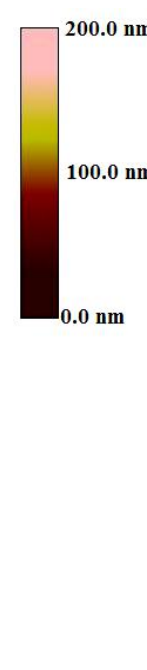

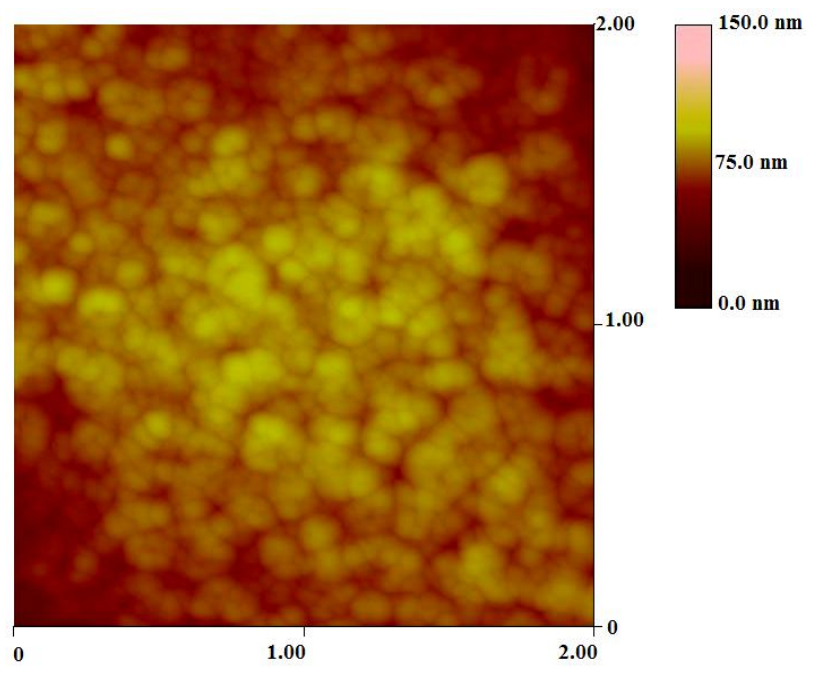

(c) $3 \%$

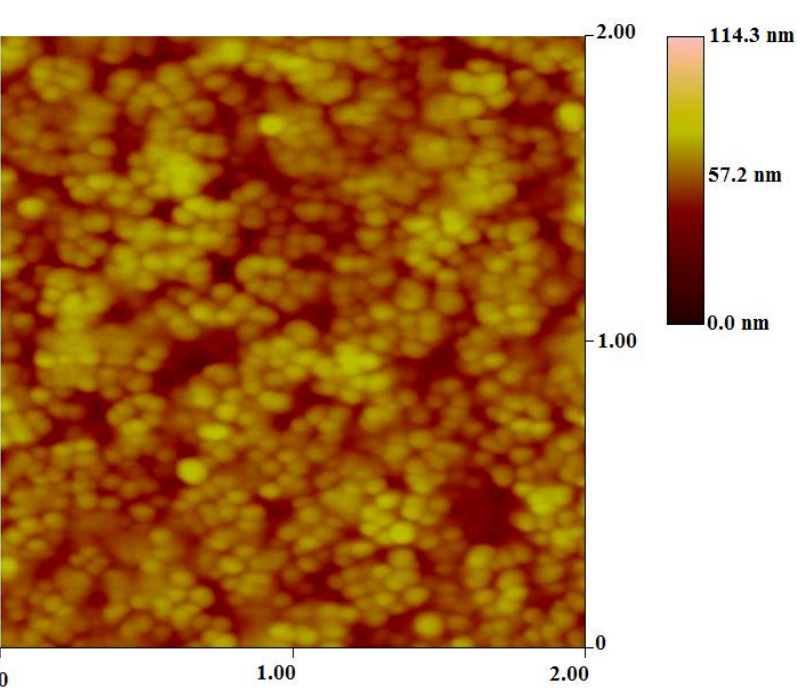

(e) $7.5 \%$

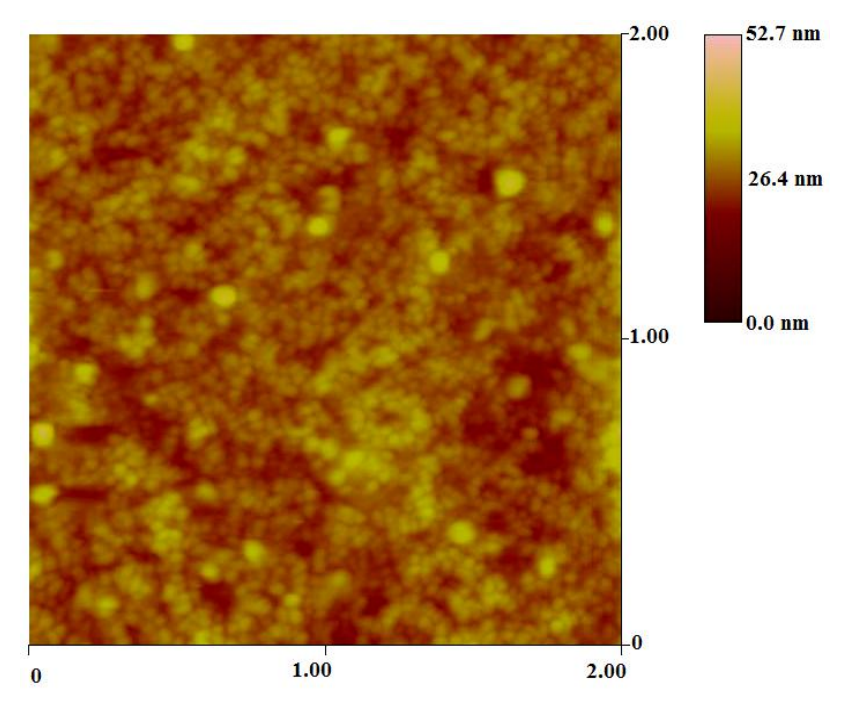

(f) $15 \%$

Figure 2. (a-f) AFM micrograph $\left(2 \times 2 \mu \mathrm{m}^{2}\right)$ of Co doped $\mathrm{ZnO}$ films at different Co doping cencentrations. 


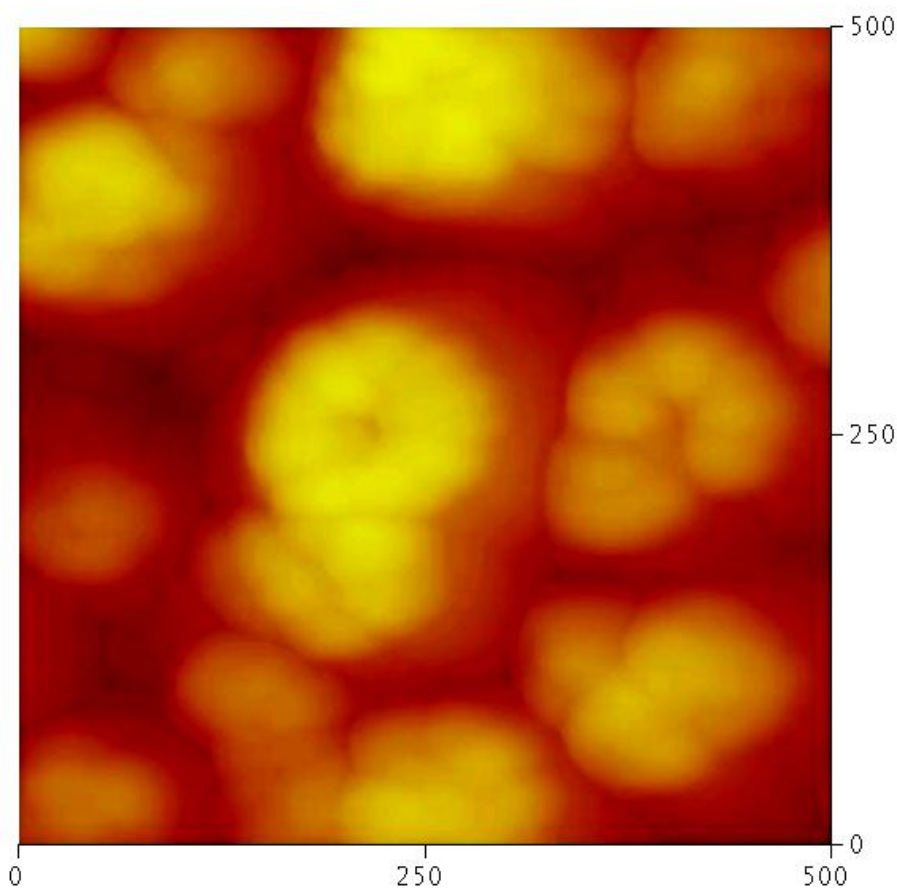

Figure 3. Self assembly of $1 \%$ Co doped $\mathrm{ZnO}$ nanoparticles (in $500 \mathrm{~nm}$ image).

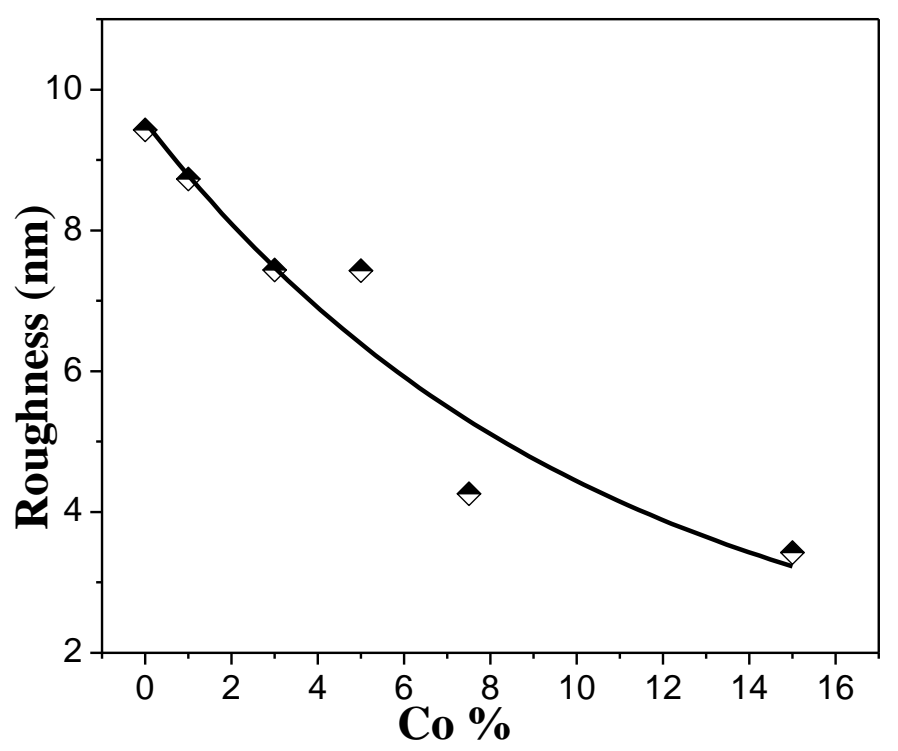

Figure 4. Roughness as a function of Co dopant percentage.

\section{Conclusion}

A systematic study has been carried out to investigate structural, morphological, electrical and optical properties of Cobalt doped $\mathrm{ZnO}$ films. All films are found to have preferred orientation along ( 002 2 $\left.\begin{array}{ll}0\end{array}\right)$ plane. However, an inclination from $\left(\begin{array}{lll}0 & 0 & 2\end{array}\right)$ to $\left(\begin{array}{lll}1 & 0 & 1\end{array}\right)$ orientation has been observed with the increase in Co doping percentage. This is because of the fact that, in addition to substitutional sites, Co may start to occupy interstitial sites due to the deformation of lattice structure caused by substitution of nearby $\mathrm{Zn}$ atoms by other Co atoms which also result in 


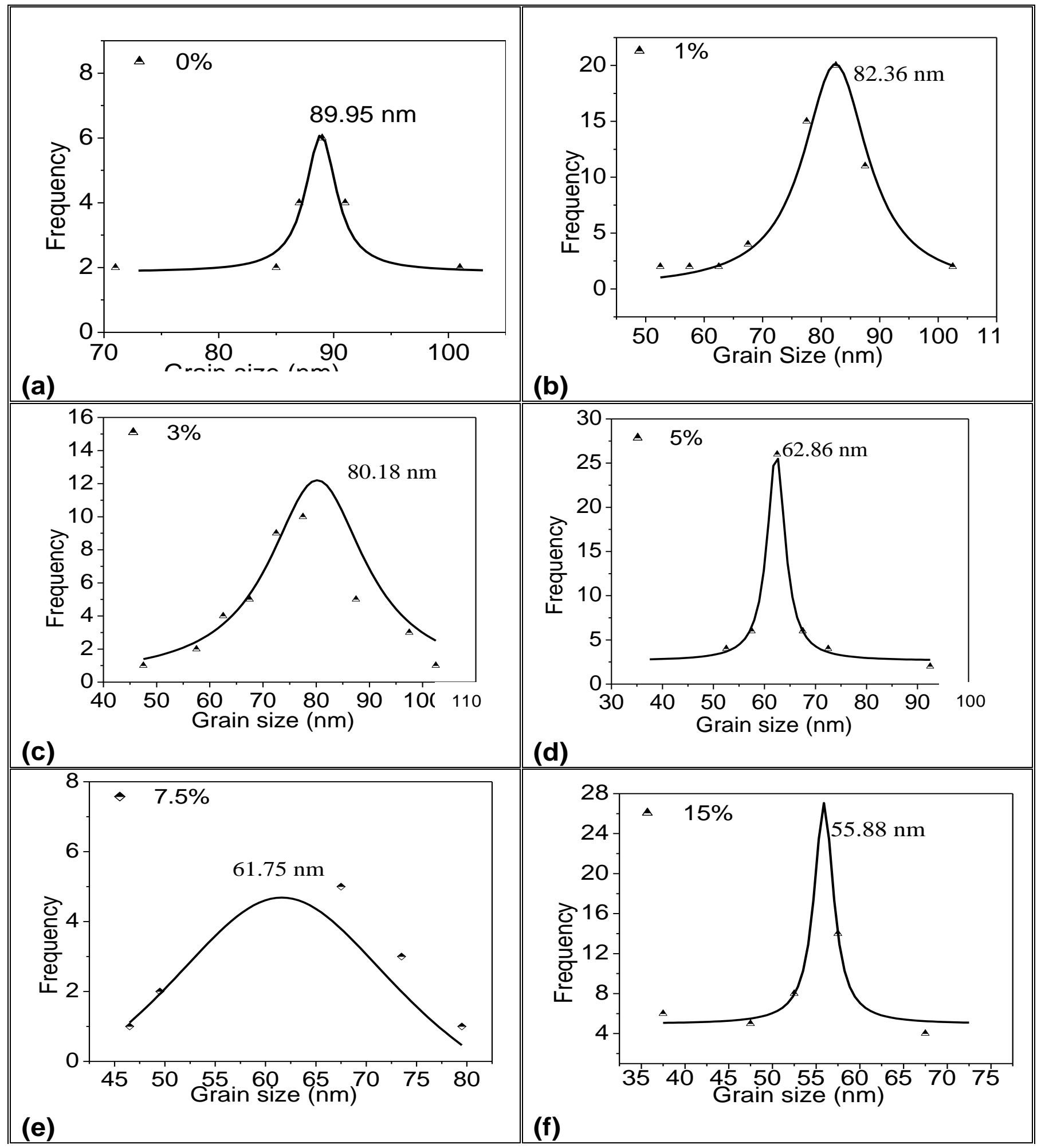

Figure 5. Grain size distributions for Co doped ZnO films for (a) 0 (b) 1 (c) 3 (d) 5 (e) 7.5 (f) $15 \%$ Co concentration.

of lattice constant. The films appear to be homogeneous and single-phase material, where cobalt enters the $\mathrm{ZnO}$ structure as $\mathrm{Co}^{2+}$ rather than forming metallic clusters.
Self-assembly of Co doped $\mathrm{ZnO}$ particles are clearly displayed in AFM micrograph. Optical transmittance spectra showed red shift at higher doping. Optical band 

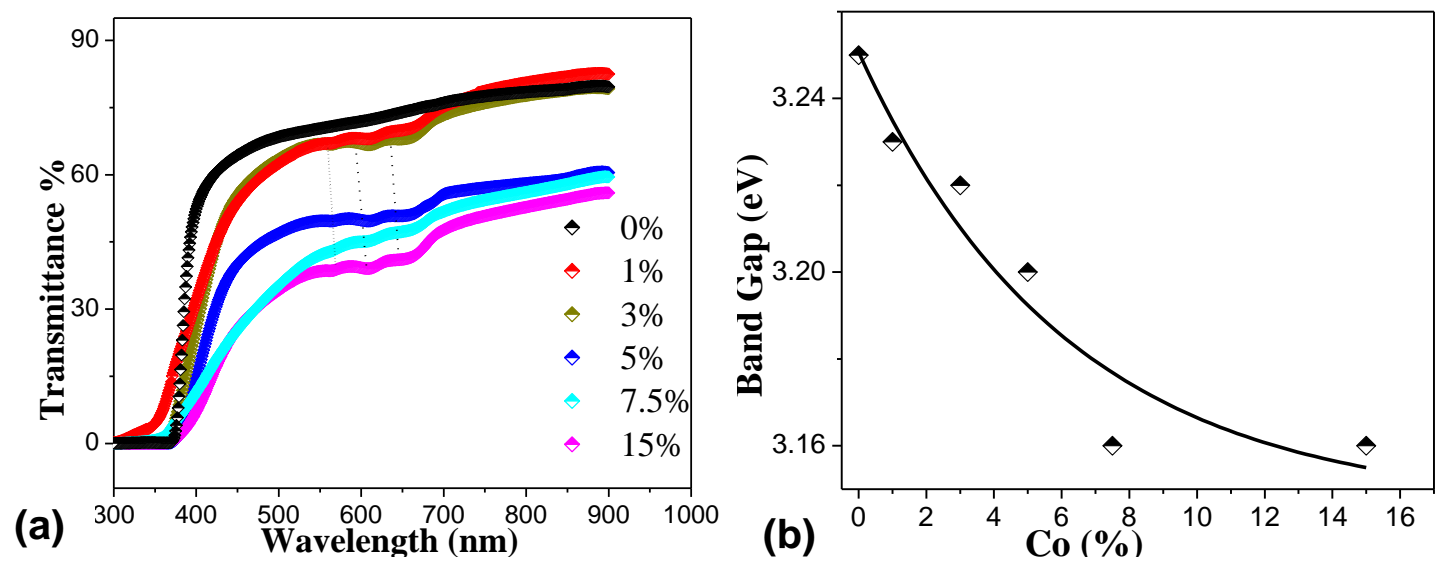

Figure 6. (a) Optical transmittance spectra of Co doped $\mathrm{ZnO}$ films (b) Optical band gap Vs Co\% curve for Co doped $\mathrm{ZnO}$ thin films.

gap values are found in the interval between 3.26 to 3.16 $\mathrm{eV}$. Resistance are found to decrease at $15 \%$ of Cobalt doping.

\section{ACKNOWLEDGEMENTS}

One of the author GS from Ujjain would like to thank UGC-DAE,CSR, Indore Center for providing the experimental facilities, and MPCST, Bhopal for finanacial assistant under the programme FTYS.

\section{REFERENCES}

Asahi R, Morikawa T, Ohwaki T, Aoki K, Taga Y (2001). Visible-light photocatalysis in nitrogen-doped titanium oxides. Science 293:269.

Diouri J, Lascaray JP, El Amrani M (1985). Effect of the magnetic order on the optical-absorption edge in Cd1-xMnxTe Phys. Rev. B 31:7995.

Ekambaram S, likubo Y, Kudo A (2007). Combustion synthesis and transition metal-incorporated ZnO. J. Alloys Compd. 433:237.

Hoffmann MR, Martin ST, Choi WY, Bahnemann DW (1995). Environmental Applications of Semiconductor Photocatalysis. Chem. Rev. 95:69.

Kim KJ, Park YR (2002). Strong p-d exchange interaction intermediated by the mobile holes Appl. Phys. Lett. 81:1420.

Li D, Haneda H (2004). Enhancement of photocatalytic activity of sprayed nitrogen-containing $\mathrm{ZnO}$ powders by coupling with metal oxides during the acetaldehyde decomposition. Chemosphere, $54: 1099$.
Liao SC, Lin HF, Hung SW, Hu CT (2006). dc thermal plasma synthesis and properties of zinc oxide nanorods. J. Vac. Sci. Technol. B24:1332.

Maureen T, Yihong W, Gu CH, Tow CC, Yuan KZ, Shi JW, Yanbin C, Xiaoqing $P$ (2006). Ferromagnetism in inhomogeneous $\mathrm{Zn1-xCoxO}$ thin films. J. Appl. Phys. 100:063910.

Mozia S, Tomaszewska M, Kosowska B, Grzmil B, Morawski AW, Kalucki K (2005). Decomposition of nonionic surfactant on a nitrogendoped photocatalyst under visible-light irradiation. Appl. Catal. B 55:195.

Nakano Y, Morikawa T, Ohwaki T, Taga Y (2005). Deep-level characterization of $\mathrm{N}$-doped $\mathrm{ZnO}$ films prepared by reactive magnetron sputtering. Appl. Phys. Lett. 87:232104.

Qiu XQ, Li LP, Li GS (2006). Doping effects of $\mathrm{Co}^{2+}$ ions on $\mathrm{ZnO}$ nanorods and their photocatalytic properties. Appl. Phys. Lett. 88:114103.

Sayilkan H (2007). Improved photocatalytic activity of $\mathrm{Sn}^{4+}$-doped and undoped $\mathrm{TiO}_{2}$ thin film coated stainless steel. Appl. Catal. A 319:230.

Wang RH, Xin JHZ, Yang Y, Liu HF, Xu LM, Hu JH (2004). Structural, Electronic, and Optical Properties of Ag-Doped ZnO Nanowires: First Principles Study. Appl. Surf. Sci. 227:312.

Wang YW, Zhang LZ, Deng KJ, Chen XY, Zou ZG (2007). $\mathrm{TiO}_{2}$ Nanoparticles with Tetra-pad Shape Prepared by an Economical and Safe Route at very Low Temperature. J. Phys. Chem. C111:2709.

$\mathrm{Wu}$ JJ, Tseng $\mathrm{CH}$ (2006). Photocatalytic properties of nc-Au/ZnO nanorod composites. Appl. Catal. B66:51. 